\title{
Dyeing Industry Effluent System as Lipid Production Medium of Neochloris sp. for Biodiesel Feedstock Preparation
}

\author{
Vidyadharani Gopalakrishnan and Dhandapani Ramamurthy \\ Fermentation Technology Lab, Department of Microbiology, Periyar University, Salem-11, Tamil Nadu 636011, India \\ Correspondence should be addressed to Dhandapani Ramamurthy; danpani@gmail.com
}

Received 27 February 2014; Revised 28 July 2014; Accepted 11 August 2014; Published 27 August 2014

Academic Editor: Nuri Azbar

Copyright (C) 2014 V. Gopalakrishnan and D. Ramamurthy. This is an open access article distributed under the Creative Commons Attribution License, which permits unrestricted use, distribution, and reproduction in any medium, provided the original work is properly cited.

\begin{abstract}
Microalgae lipid feedstock preparation cost was an important factor in increasing biodiesel fuel hikes. This study was conducted with the concept of implementing an effluent wastewater as lipid production medium for microalgae cultivation. In our study textile dyeing industry effluent was taken as a lipid production medium for Neochloris sp. cultivation. The changes in physicochemical analysis of effluent before and after Neochloris sp. treatment were recorded using standard procedures and AAS analysis. There was especially a reduction in heavy metal like lead $(\mathrm{Pb})$ concentration from $0.002 \mathrm{ppm}$ to $0.001 \mathrm{ppm}$ after Neochloris sp. treatment. Neochloris sp. cultivated in Bold Basal Medium (BBM) (specific algal medium) produced $41.93 \%$ total lipid and $36.69 \%$ lipid was produced in effluent based cultivation. Surprisingly Neochloris sp. cultivated in effluent was found with enhanced neutral lipid content, and it was confirmed by Nile red fluorescence assay. Further the particular enrichment in oleic acid content of the cells was confirmed with thin layer chromatography (TLC) with oleic acid pure (98\%) control. The overall results suggested that textile dyeing industry effluent could serve as the best lipid productive medium for Neochloris sp. biodiesel feedstock preparation. This study was found to have a significant impact on reducing the biodiesel feedstock preparation cost with simultaneous lipid induction by heavy metal stress to microalgae.
\end{abstract}

\section{Introduction}

Algae comprise a wide variety of photosynthetic heterotrophic organisms that belong to different phylogenetic groups, denoting many taxonomic divisions. They are inhabited predominantly in fresh and marine water ecosystems. Among them microalgae are predominant in both marine and freshwater ecosystems. They contribute to more than half of the total primary production at the bottom level of the food chain [1]. Most of the microalgae can survive and proliferate in a wide range of environmental conditions due to their secondary metabolite acquisition. Thus microalgae gained more attention in the food, aquaculture, fuel, and biotechnology industries [2].

Environmental issue of industrial effluents and their concomitant deposition in discharging land and water system led to severe obstruction in the ecosystem. Particularly the heavy metal load in effluents is considered to be toxic and high level pollutants of water systems. The unknown exposure of these metals to humans leads to many hereditary diseases and cancer. In order to eliminate the adverse effects of these heavy metal constituents, proper treatment and recycling of the effluent are important. Also simultaneous reduction of other physicochemical parameters in effluent water that disturbs environmental stability should also be considered. Mostly the time consuming effluent treatment processes result in an economic crisis to the industrial sectors. Our natural system has its own candidates such as bacteria, fungi, and algae to remove these anthropogenic factors.

By conventional physical and chemical technologies such as membrane filtration, coagulation, precipitation, floatation, adsorption, ion exchange, chemical reduction, ultrasonic mineralization, electrolysis, and advanced chemical oxidation the effluents are treated. Some of these methods are termed to be effective; also they possess underlying drawbacks such as high cost, intensive energy requirements, and formation of hazardous byproducts and generation of sludge which causes secondary pollution [3]. In order to 
avoid these effects, specific attention should be given to biological treatment processes because of their cost-effective and ecofriendly characteristics. Next to bacteria, microalgae are important candidates in treating industrial effluents due to their ability to adapt in adverse conditions.

Generally algae lipids can be classified into two major groups, namely, the nonpolar lipids (acylglycerol, sterol, free fatty acids, hydrocarbons, wax, and steryl esters) and polar lipids (phosphoglycerides, glycosylglycerides) [4]. Each of the lipid constituents has its own important function. For instance, polar lipids and some sterols are playing an essential role in biological membrane construction. It helps in the membrane permeability and provides a barrier between organelles within cells. Also, they are involved in cell signaling pathways (e.g., inositol lipids, sphingolipids, and oxidative products of polyunsaturated fatty acids). The nonpolar lipids mainly triacylglycerols (TAG) serve as an abundant energy storing material which can be easily catalyzed to provide metabolic energy.

Enhancing microalgae lipid production is necessary to reduce the biodiesel feedstock cost and its sustainability. A number of green microalgae strains can accumulate large quantities of lipids under nutrient stress. They are appearing to be the sustainable source of biodiesel that has great potential to replace fossil diesel. The oil content of microalgae may range from 16 to $68 \%$ dry weight and the oil yield from microalgae can reach up to $136,900 \mathrm{~L} /$ ha compared to other plant crops, which range from 172 to $5950 \mathrm{~L} / \mathrm{ha}$ [5]. Further optimization of culture conditions can enhance the lipid content of microalgae. Some of the microalgae members can accumulate triglycerides as storage lipid up to $70 \%$ dry weight under nitrogen starvation.

For instance Neochloris oleoabundans is a microalga that can accumulate lipid up to $54 \%$ in its total dry cell weight [5]. Under adverse conditions like nitrogen depletion microalgae cells are accumulating lipid due to their change in metabolic pathways. In such condition triacylglycerides (TAGs) are the more preferable lipid than any other types of lipid. Based on the favorable features Neochloris sp. is preferred for the present work. Instead of depleting nutrients we attempted to give heavy metal stress through industrial effluent based cultivation. Textile dyeing industry effluent was selected for the present work due to their heavy metal load. This study revealed that lead $(\mathrm{Pb})$ content in effluent influenced TAGs storage in Neochloris sp. It was confirmed by thin layer chromatography (TLC) and Nile red fluorescence imaging and quantification. Further optimization of the strain with desirable parameters during effluent based cultivation will be helpful for increased TAG production.

\section{Materials and Methods}

2.1. Cultivation Neochloris sp. The Neochloris sp. AY2 strain was obtained from the Fermentation Technology Lab in the Department of Microbiology at the Periyar University, located in Salem district, Tamil Nadu, India. $5 \mathrm{~mL}$ culture was inoculated in $250 \mathrm{~mL}$ Bold Basal Medium (BBM) and incubated at $25^{\circ} \mathrm{C}$ under 1500 Lux white fluorescent light illumination for 21 days. The culture was examined in $400 \mathrm{x}$ magnification under a light microscope and its purity was confirmed [6].

2.2. Characterization of Effluent Sample. Textile dyeing industry effluent was collected from local yawn dyeing industry located in Karur district and the effluent sample physicochemical properties of the effluent sample were analyzed by the following APHA protocol published in 1994. Heavy metals were analyzed using atomic adsorption spectroscopy (AAS).

2.3. Screening of Neochloris sp. in Textile Dyeing Industry Effluent. From the grown Neochloris sp. $10 \mathrm{~mL}$ of culture was drawn initially, inoculated in $200 \mathrm{~mL}$ of sterile raw effluent, and kept at $25^{\circ} \mathrm{C}$ under 1500 Lux illumination for 21 days. The adaptation of Neochloris sp. was confirmed after 14 days by Evan's blue staining [7]. The effluent was observed for physicochemical change after cultivation with Neochloris sp.

\subsection{Lipid Extraction and Characterization}

2.4.1. Total Lipid Extraction. The total lipid sample was extracted from algal culture by Bligh and Dyer method, 1957. $10 \mathrm{~mL}$ of algae suspension was centrifuged at 3,800 RPM for 10 minutes to obtain a concentrated algae paste. The recorded dry cell weight (DCW) of the biomass was determined gravimetrically after drying at $60^{\circ} \mathrm{C}[8]$. The extracted lipids were quantified to know the lipid producing ability of the strain (Figure 4). The lower layer was filtered through a Whatman number 1 filter into a previously weighed glass vessel $\left(W_{1}\right)$ with the help of a glass syringe. The solvent was dried in a water bath at $98^{\circ} \mathrm{C}$ and the vessel was weighed again $\left(W_{2}\right)$. The lipid content of the sample was calculated using the following formula:

$$
\text { Lipid content }=\frac{W_{1}-W_{2}}{W_{d}} \times 100 \%
$$

2.4.2. Thin Layer Chromatography (TLC). The crude lipid extract was analyzed through thin layer chromatography with the help of saturated solvents, namely, hexane: diethyl ether:acetic acid 60:40:1. After running the TLC plate neutral lipids were stained using iodine vapors and viewed in visible light [9].

2.4.3. Nile Red Fluorescence Assay. The microalgal cells were stained with Nile red (Sigma Aldrich) as described by Chen et al., 2009 [6], for fluorescent spectroscopy analysis. The emissions were measured as a potential fluorescence unit (PFU) in every two-day interval. To the $3 \mathrm{~mL}$ of culture $15 \mu \mathrm{L}$ aliquot of $7.8 \mu \mathrm{M}$ Nile red dissolved in acetone was added. The emission wavelength was measured at $570 \mathrm{~nm}$. Fluorescence intensity was recorded over a period of 30 seconds. The neutral lipid concentrations in live stained cells were estimated. 


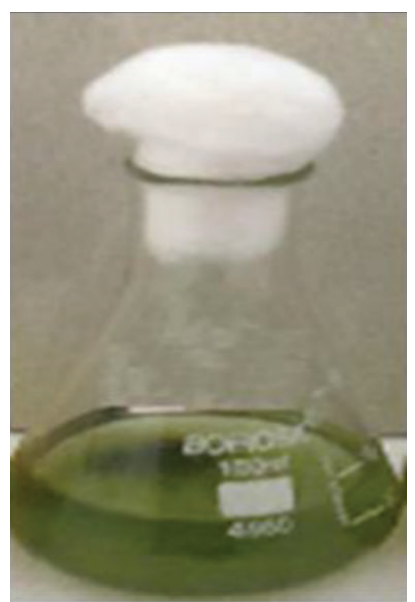

Figure 1: Grown culture of Neochloris sp. (after 21-day incubation).

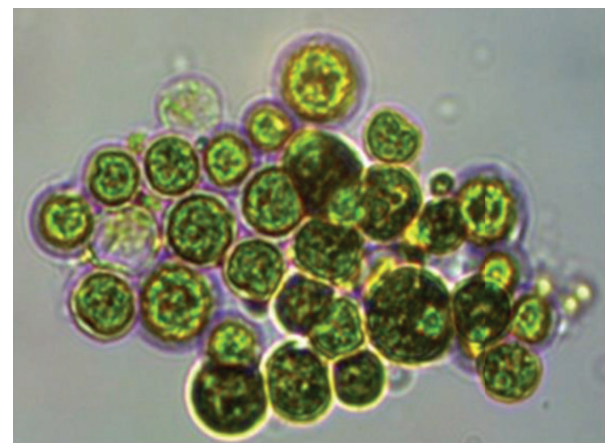

Figure 2: Microscopic appearance on Neochloris sp. in 1000x magnification under oil immersion.

\section{Results}

3.1. Neochloris sp. Cultivation. The obtained Neochloris sp. was initially cultivated in $200 \mathrm{~mL} \mathrm{BBM}$ (Figure 1) and kept at $25^{\circ} \mathrm{C}$ under 1500 Lux illumination for 21 days, and subsequent microscopic observations were performed to know the purity of the strain. The microscopic image (Figure 2) showed the microscopic appearance of Neochloris sp. cultivated in BBM after 21-day incubation. Biomass estimation studies were carried out initially and total lipids were extracted from the grown culture to know the native ability of the strain in lipid production.

3.2. Effluent Sample Characterizations. Textile effluent sample from local dyeing industry located in Karur district was stored in $4^{\circ} \mathrm{C}$ until processing. The physicochemical characterization was done for the effluent by standard APHA protocol [6]. Heavy metal analysis was performed with atomic absorption spectroscopy. The results were listed in Table 1 . The strain was subjected to sterile $100 \%$ (raw) effluent; the adaptability was checked with the help of $1 \%$ Evan's blue dye. This is a good choice of stain for live-dead determination. Cells that contained intact semipermeable membrane (live) refused the dye and the dye penetrated the dead cells only.

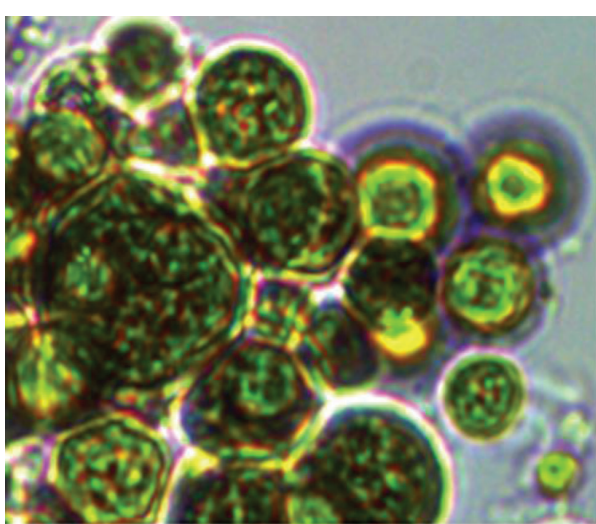

Figure 3: Microscopic appearance of Evan's blue stained Neochloris sp. under 400x illumination.

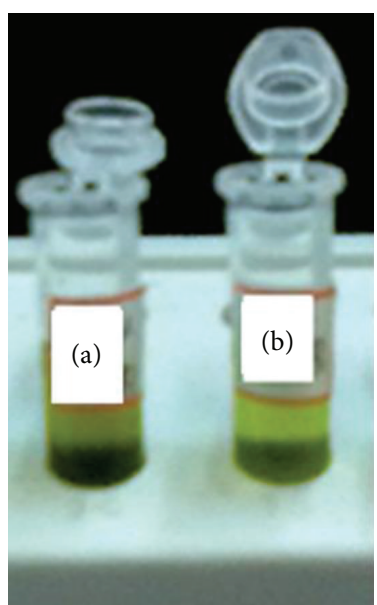

FIgURE 4: Total lipid extract: (a) Neochloris sp. cultivated in BBM and (b) Neochloris sp. cultivated in effluent.

Therefore Evans's blue was referred to as a mortal strain rather than a vital strain [7] (Figure 3).

3.3. Total Lipid Extraction and Quantification. Total lipid was extracted from Neochloris sp. (Figure 4) cultivated in BBM and Neochloris sp. cultivated in effluent.

According to the estimation, total lipid percentage was higher in BBM grown Neochloris sp. up to $41.93 \%$ than effluent grown Neochloris sp. that produced lipid up to $36.69 \%$ (Table 2). When considering total lipid productivity, BBM would be chosen as a suitable productive medium for lipid feedstock preparation.

3.4. Thin Layer Chromatography Analysis. The lipid extracts were analyzed using thin layer chromatography. The TLC plates were analysed (Figure 7) after spraying with iodine vapors for separated compounds. Iodine vapors were used to view nonpolar lipid such as triglyceride substances [9], and it was confirmed with appropriate standards. In total crude extract there was a peak, which showed the nearest Rf value 
TABle 1: Physicochemical parameters of the textile dyeing industry effluent before and after treatmentwith Neochloris sp.

\begin{tabular}{lccr}
\hline S. number & Parameter and heavy metals & \multicolumn{2}{c}{$\begin{array}{c}\text { Experimental value textile dyeing industry effluent } \\
\text { Treated with Neochloris sp. }\end{array}$} \\
\hline 1. & $\mathrm{pH}$ & 10.3 & 7.9 \\
2. & Total dissolved solids & $3240(\mathrm{ppm})$ & $990(\mathrm{ppm})$ \\
3. & Total suspended solids & $804(\mathrm{ppm})$ & $236(\mathrm{ppm})$ \\
5. & Total hardness & $1992(\mathrm{ppm})$ & $581(\mathrm{ppm})$ \\
6. & Total alkalinity & $1025(\mathrm{ppm})$ & $193(\mathrm{ppm})$ \\
8. & Dissolved oxygen & $13.2(\mathrm{ppm})$ & $19.7(\mathrm{ppm})$ \\
9. & $\mathrm{BOD}$ & $923(\mathrm{ppm})$ & $225(\mathrm{ppm})$ \\
10. & $\mathrm{COD}$ & $5680(\mathrm{ppm})$ & $1962(\mathrm{ppm})$ \\
11. & $\mathrm{~Pb}$ & $0.002(\mathrm{ppm})$ & $0.001(\mathrm{ppm})$ \\
12. & $\mathrm{Cr}$ & $0.005(\mathrm{ppm})$ & $0.005(\mathrm{ppm})$ \\
13. & $\mathrm{Ni}$ & $0.001(\mathrm{ppm})$ & $0.001(\mathrm{ppm})$ \\
14. & $\mathrm{Zn}$ & $0.006(\mathrm{ppm})$ & $0.006(\mathrm{ppm})$ \\
15. & $\mathrm{Cd}$ & $0.000(\mathrm{ppm})$ & $0.000(\mathrm{ppm})$ \\
16. & $\mathrm{Cu}$ & $0.000(\mathrm{ppm})$ & $0.000(\mathrm{ppm})$ \\
17. & $\mathrm{Al}$ & $0.000(\mathrm{ppm})$ & $0.000(\mathrm{ppm})$ \\
18. & $\mathrm{Hg}$ & $0.000(\mathrm{ppm})$ & $0.000(\mathrm{ppm})$ \\
\hline
\end{tabular}

TABLE 2: Table showing the total lipid percentage in Neochloris sp.

\begin{tabular}{lcccccc}
\hline S. number & Microalgae strain & Cultivation medium & $\begin{array}{c}\text { Dry cell weight } \\
(\mathrm{DCW})(\mathrm{in} / \mathrm{L})\end{array}$ & $\begin{array}{c}\text { Lipid filtrate } \\
\text { weight }\left(W_{1}\right)(\mathrm{g} / \mathrm{L})\end{array}$ & $\begin{array}{c}\text { Dry lipid weight } \\
\left(W_{2}\right)(\mathrm{g} / \mathrm{L})\end{array}$ & $\begin{array}{c}\text { Total lipid content } \\
(\mathrm{in} \%)\end{array}$ \\
\hline 1. & Neochloris sp. & BBM & 88 & 0.93 & 0.561 & 41.93 \\
2. & Neochloris sp. & Effluent sample I & 109 & 2.7 & 2.3 & 36.69 \\
\hline
\end{tabular}

for oleic acid 0.8 , and it was confirmed by oleic acid standard peak.

3.5. Nile Red Fluorescent Spectroscopy Assay. This method was quite helpful in confirming the presence of in vivo neutral lipid content and its estimation in microalgae cells (Figure 5). Based on the results the Neochloris sp. could be further optimized. The Nile red stained cells were observed for yellow fluorescent spots that denote neutral lipid under fluorescent microscopy [6]. The emission wavelength was measured at $570 \mathrm{~nm}$, and the recorded potential fluorescent units from fluorescent spectroscopy were recorded for every two-day time interval.

The fluorescence spectroscopy based Nile red assay was interpreted with the correlation value with the two variables such as PFU and the number of days. It gave an important notification on neutral lipid quantity inside the live Neochloris sp. In case of BBM grown Neochloris sp. the $R^{2}$ value is 0.155 (Figure 6(b)) and is highly negligible and denoted the less quantity of neutral lipid content. In effluent grown Neochloris sp. the $R^{2}$ value reached up to 0.819 (Figure 6(a)), and it denoted the increased neutral lipid content in the live algal cells.

\section{Discussion}

This study was started with the concept of implementing textile dyeing industry effluent as lipid production medium for microalgae. The adaptation of algae to different environmental conditions was reflected in an exceptional variety of lipids as well as a number of unusual compounds. Most of the algae could accumulate nonpolar lipid, especially in the form of TAG, a preferable biodiesel feedstock, up to $20-50 \%$ of dry cell weight [5]. This property gave an important position for algae in the renewable energy sector, and it was considered to be the potent source of biofuel. Lipids act as secondary metabolite in microalgae, maintaining specific membrane functions and cell signaling pathways while responding to the environment changes. Mostly TAG cellular accumulation corresponds to a shift in metabolism under unfavorable environmental conditions.

When compared to other industrial polluters textile dyeing industries are known to generate only a small fraction of total liquid effluent, but they may contribute a high proportion of total contaminants [10]. Textiles dyeing effluents was highly colored, contains saline, non biodegradable compounds, and with high oxygen demand (OD). It has been reported that the presence of metal and other dye compounds inhibits microbial activity and some cases that may cause failure of biological treatment systems.

Microalgae wastewater treatment was ecofriendly and offers the advantage of a cost-effective way of nutrient removal and biomass production. Textile dyeing industries are utilizing higher volume of water that finally results in an abundant wastewater generation; these are the major water polluting sources of ecosystem [11]. In 1974 EPA reported 


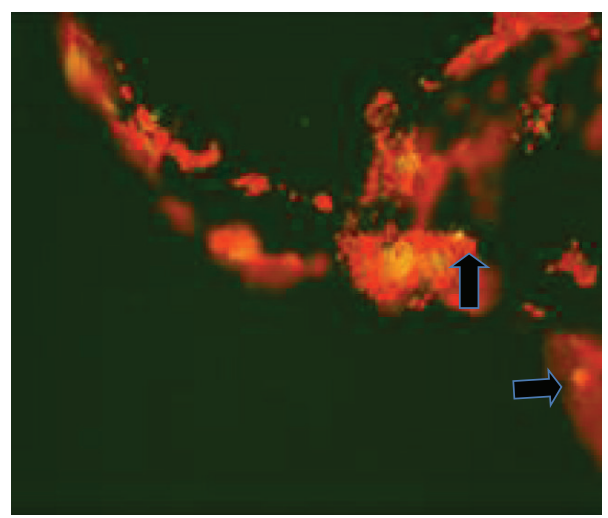

(a)

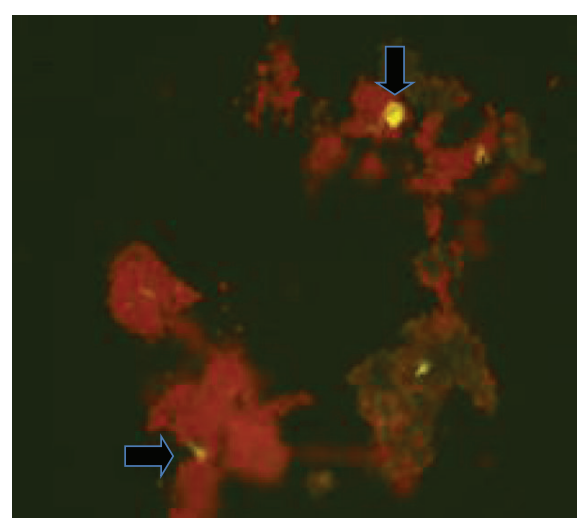

(b)

FIGURE 5: Nile red fluorescence microscopic images: (a) Neochloris sp. cells cultivated in effluent medium and (b) Neochloris sp. cells cultivated in BBM.

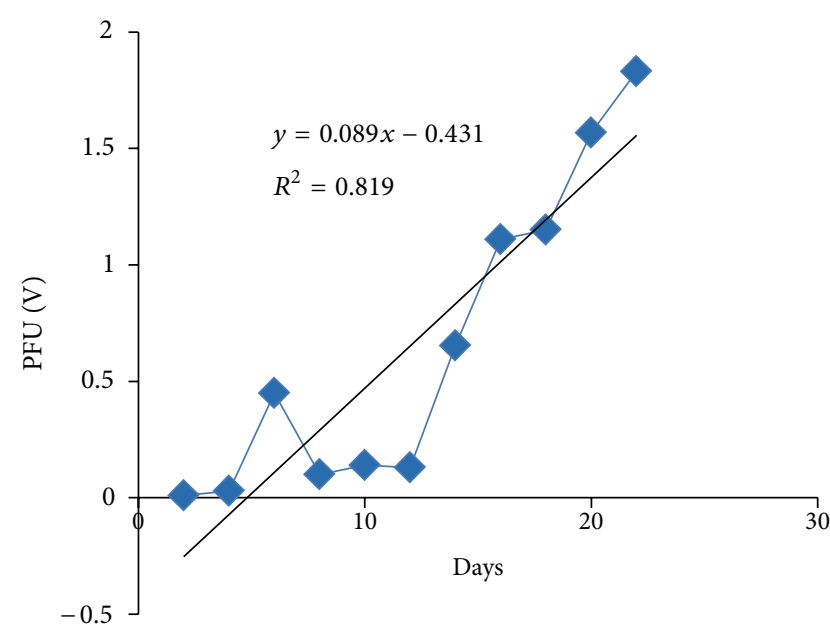

(a)

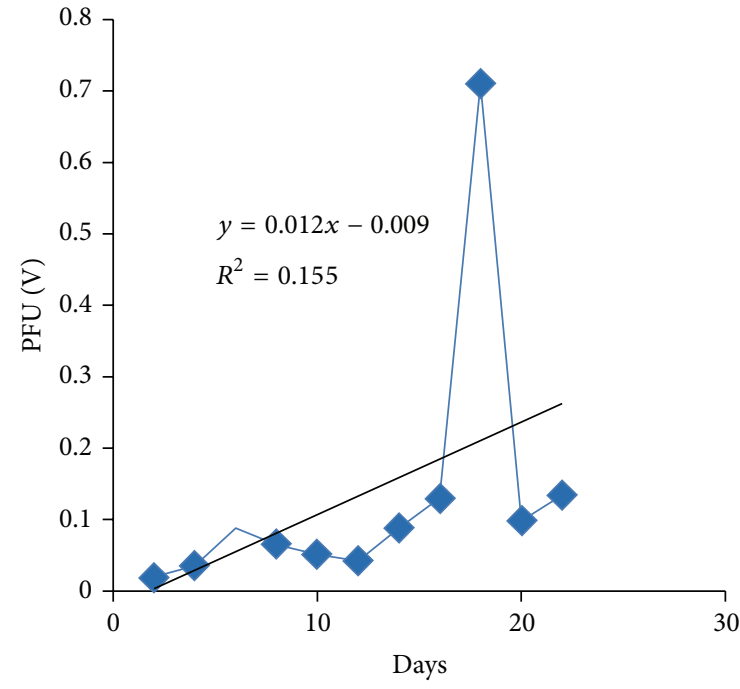

(b)

FIGURE 6: Nile red fluorescent assay based neutral lipid estimation. (a) Neochloris sp. cultivated in Effluent and (b) Neochloris sp. cultivated in BBM.

that the pollution parameters in textile wastewater effluents are suspended solids, BOD, COD, nitrogen, phosphate, temperature, and toxic chemicals such as phenolic compounds and heavy metals, $\mathrm{pH}$, alkalinity, acidity, oils and grease, and sulfides. Still, it is an undoable task to treat textile effluent completely due to the presence of synthetic dyes that are difficult to remove by conventional methods.

These issues were taken into account and our study was targeted to treat the textile dyeing industry effluent for Neochloris sp. cultivation. This study was reported to be the first study on screening of Neochloris sp. in textile dyeing industry effluent for lipid production.

The following changes were recorded before and after Neochloris sp. cultivation in textile dyeing industry effluent.
The $\mathrm{pH}$ was recorded as 10.3 initially which was an unsupportive factor for microalgae growth, and still we made an attempt to cultivate microalgae. Later on the $\mathrm{pH}$ was reduced up to 7.9 after 21 days of Neochloris sp. cultivation. Physicochemical properties were compared in between treated and untreated effluents and mentioned as follows. Likewise the total dissolved solids which were at $3240 \mathrm{ppm}$ in raw effluent were reduced to $994 \mathrm{ppm}$, and total suspended solids which were at $804 \mathrm{ppm}$ were reduced to $236 \mathrm{ppm}$. Initial total hardness was $1992 \mathrm{ppm}$ that reduced to $581 \mathrm{ppm}$. Total alkalinity was $1025 \mathrm{ppm}$ and reduced to $193 \mathrm{ppm}$. Dissolved oxygen was in the range of $13.2 \mathrm{ppm}$ that was raised up to $19.7 \mathrm{ppm}$. Biological oxygen demand (BOD) at $923 \mathrm{ppm}$ was reduced to $225 \mathrm{ppm}$. Chemical oxygen demand (COD) at 


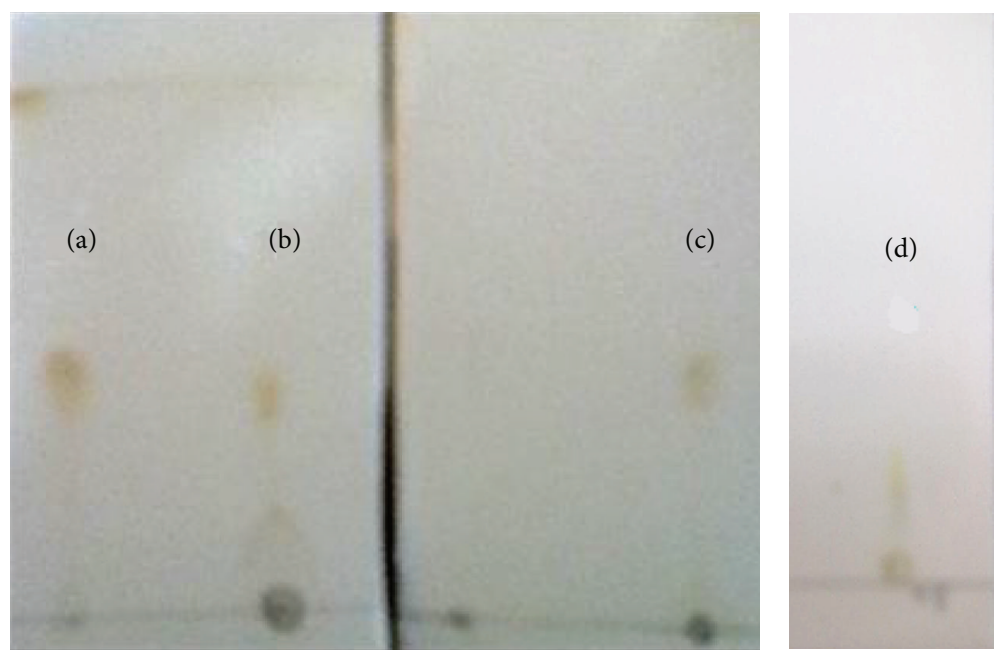

Figure 7: Thin layer chromatography plates for lipid extract from Neochloris sp. (a) Lipid from Neochloris sp. cultivated in effluent after 14 days, (b) lipid from Neochloris sp. cultivated in effluent after 21 days, (c) oleic acid control, and (d) lipid from Neochloris sp. cultivated in BBM after 21 days.

5680 ppm was tremendously reduced to $1962 \mathrm{ppm}$. The AAS analysis report for untreated effluent revealed the presence of lead $(\mathrm{Pb})$ at $0.002 \mathrm{ppm}$, chromium $(\mathrm{Cr}) 0.005 \mathrm{ppm}$, and nickel (Ni) 0.001. Other heavy metals such as zinc, cadmium, copper, and aluminium were absent in the effluent sample. In treated effluent, heavy metal lead $(\mathrm{Pb})$ was reduced to $0.001 \mathrm{ppm}$, whereas other heavy metal reduction was not observed.

Also the tolerance level of the Neochloris sp. for lead $(\mathrm{Pb})$ concentration of $0.002 \mathrm{ppm}$ was verified using Evan's blue staining. This staining method revealed the viability of Neochloris sp. in textile dyeing industry effluent. The hazardous parameters, color, and $\mathrm{pH}$ were reduced after Neochloris sp. treatment of the effluent. In our study we have concentrated on neutral lipid induction, and especially we found to know the reduction in $\mathrm{Pb}$ level from 0.002 to $0.001 \mathrm{ppm}$ and increased neutral lipid content of Neochloris sp., the mechanism was still unknown. Further Nile red assay confirmed the neutral lipid analysis. The total lipid produced when Neochloris sp. was grown on BBM was $41.93 \%$ and the effluent grown Neochloris sp. produced lipid up to $36.69 \%$.

The Nile red fluorescence assay was quite helpful in neutral lipid estimation. The potential fluorescence unit (PFU) measurement was correlated with the number of incubation days in cultivation medium. The calculated $R^{2}$ value for Neochloris sp. cultivated in BBM was 0.155 that directly stated the less significance with the incubation period and the neutral lipid content. It denoted the lower concentration of neutral lipid content inside the cell when cultivated in BBM. Oppositely the $R^{2}$ value for Neochloris sp. cultivated in the effluent was 0.819 and stated the high relevance of the effluent medium and incubation period provided in the respective change in neutral lipid content. It indirectly denoted that some of the components in the effluent system lead to an increase in neutral lipid content.

The heavy metals such as cadmium, iron, copper, and zinc were reported previously to increase the lipid content in many microalgae. For instance, cadmium treated cells of Euglena gracilis under illumination were found with increased lipid production [12]; likewise the effect of iron on Chlorella vulgaris was studied by Liu et al., 2008 [13], who reported that total lipid content was raised up to $56.6 \%$ in total biomass. The exact mechanism was still unclear.

Further studies on lipid characterization with thin layer chromatogram revealed that the effluent grown strain can accumulate oleic acid rather than BBM grown strain. It was confirmed with the oleic acid (98\% pure) control. After obtaining this result, it had been reviewed with the physicochemical properties of the processed effluent. The changes before and after treatment with Neochloris sp. were measured; among four heavy metals that were presented in effluent medium only lead $(\mathrm{Pb})$ was utilized by the strain. The initial concentration of 0.002 in ppm was reduced to 0.001 in ppm. This was considered to be the upliftment in the neutral lipid content of the effluent grown cells, especially the oil and acid content of the cells. It has been previously reported that oleic acid content of the algal cells can be influenced by lead $(\mathrm{Pb})$. This result was added as a supportive point for utilizing textile dyeing industry effluent as lipid production medium for Neochloris sp. Only drawback was the reduction in total biomass after exponential phase. In addition, concern should be given to maintain the same growth rate of Neochloris sp. towards producing high amounts of neutral lipid in effluent based medium. Also the complementary advantage of the industrial sector was the recycled water from the effluent that could be reused in the same industry. In overview this study reported that textile dyeing industry effluent could be the best lipid productive medium for Neochloris sp. biodiesel feedstock preparation.

\section{Conflict of Interests}

The authors declare that there is no conflict of interests regarding the publication of this paper. 


\section{Acknowledgments}

The authors acknowledge the Department of Biotechnology, Government of India, for their grant and support for the present work. Also special thanks are due to Dr. C. Kannan, Head, Department of Chemistry, Government Engineering College, Salem, and his team for providing us the necessary facilities for AAS analysis, and Mr. V. Suresh, Chemist at the Department of Chemistry, Sona Engineering College, Salem.

\section{References}

[1] I. A. Guschina and J. L. Harwood, "Lead and copper effects on lipid metabolism in cultured lichen photobionts with different phosphorus status," Phytochemistry, vol. 67, no. 16, pp. 1731-1739, 2006.

[2] A. Richmond, Handbook of Microalgal Culture: Biotechnology and Applied Phycology, Blackwell Science, 2004.

[3] T. Robinson, G. McMullan, R. Marchant, and P. Nigam, "Remediation of dyes in textile effluent: a critical review on current treatment technologies with a proposed alternative," Bioresource Technology, vol. 77, no. 3, pp. 247-255, 2001.

[4] F. D. Gunstone, J. L. Harwood, and A. J. Dijkstra, Eds., The Lipid Handbook, Taylor and Francis group, Boca Raton, Fla, USA, 3rd edition, 2007.

[5] Y. Chisti, "Biodiesel from microalgae," Biotechnology Advances, vol. 25, no. 3, pp. 294-306, 2007.

[6] W. Chen, C. Zhang, L. Song, M. Sommerfeld, and Q. Hu, "A high throughput Nile red method for quantitative measurement of neutral lipids in microalgae," Journal of Microbiological Methods, vol. 77, no. 1, pp. 41-47, 2009.

[7] R. W. Crippen and J. L. Perrier, "The use of neutral red and Evans blue for live-dead determinations of marine plankton," Stain Technology, vol. 49, no. 2, pp. 97-104, 1974.

[8] O. K. Dalrymple, T. Halfhide, I. Udom et al., "Wastewater use in algae production for generation of renewable resources: a review and preliminary results," Aquatic Biosystems, vol. 9, no. 1, article 2, 2013.

[9] G. C. Shah, A. Patidar, V. Urkude et al., "Analysis and Characterization of Algal Oil by Using Different Chromatographic Techniques for the Higher Production of Biodiesel from Scenedesmus Dimorphus Algal Species," 2012.

[10] L. Wang, Y. Li, P. Chen et al., "Anaerobic digested dairy manure as a nutrient supplement for cultivation of oil-rich green microalgae Chlorella sp.," Bioresource Technology, vol. 101, no. 8, pp. 2623-2628, 2010.

[11] N. L. Nemerow, Industrial Water Pollution: Origins, Characteristics and Treatment, R. E. Krieger Publishing, 1978.

[12] M. Einicker-Lamas, G. A. Mezian, T. B. Fernandes et al., "Euglena gracilis as a model for the study of $\mathrm{Cu}^{2+}$ and $\mathrm{Zn}^{2+}$ toxicity and accumulation in eukaryotic cells," Environmental Pollution, vol. 120, no. 3, pp. 779-786, 2002.

[13] Z. Y. Liu, G. C. Wang, and B. C. Zhou, "Effect of iron on growth and lipid accumulation in Chlorella vulgaris," Bioresource Technology, vol. 99, no. 11, pp. 4717-4722, 2008. 

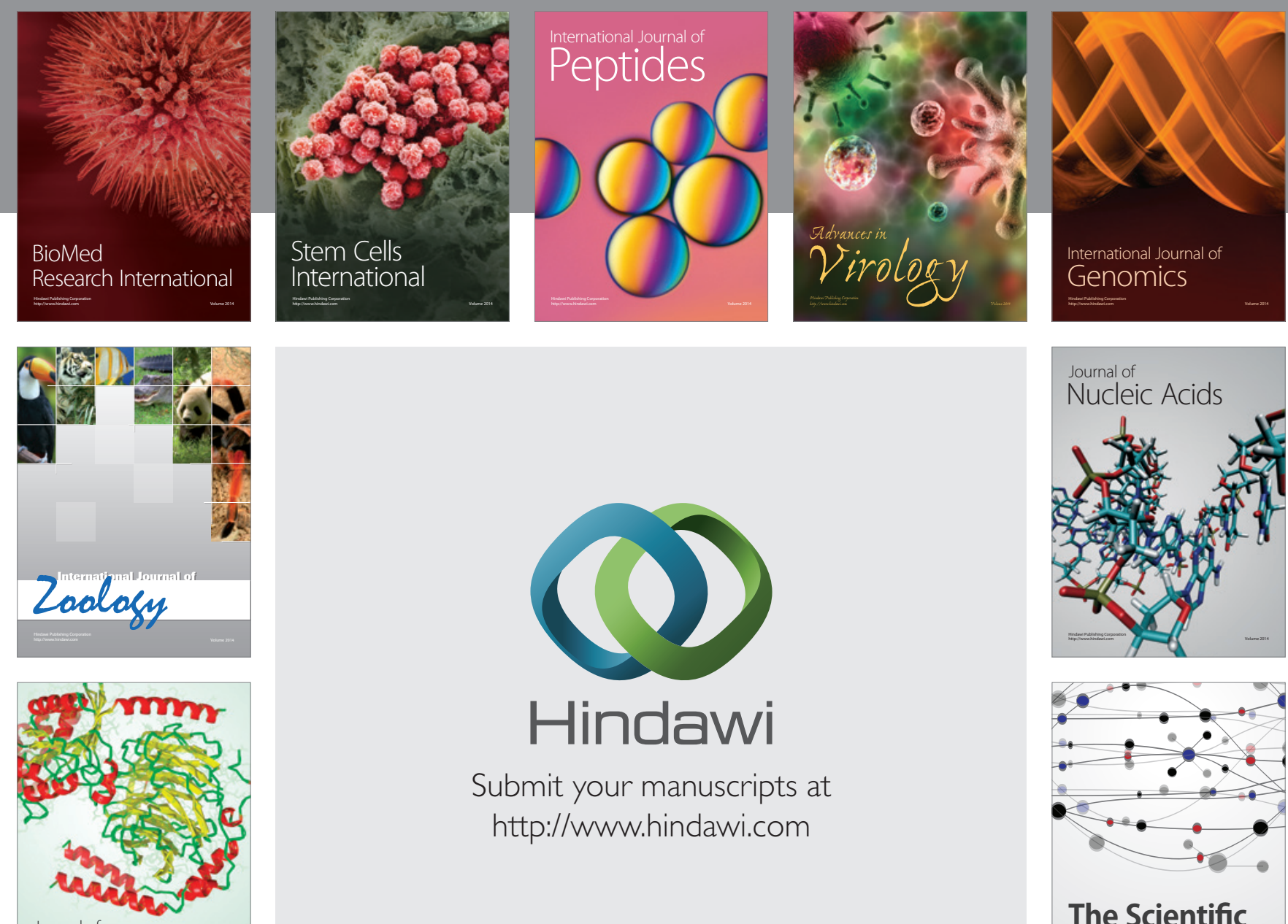

Submit your manuscripts at

http://www.hindawi.com

Journal of
Signal Transduction
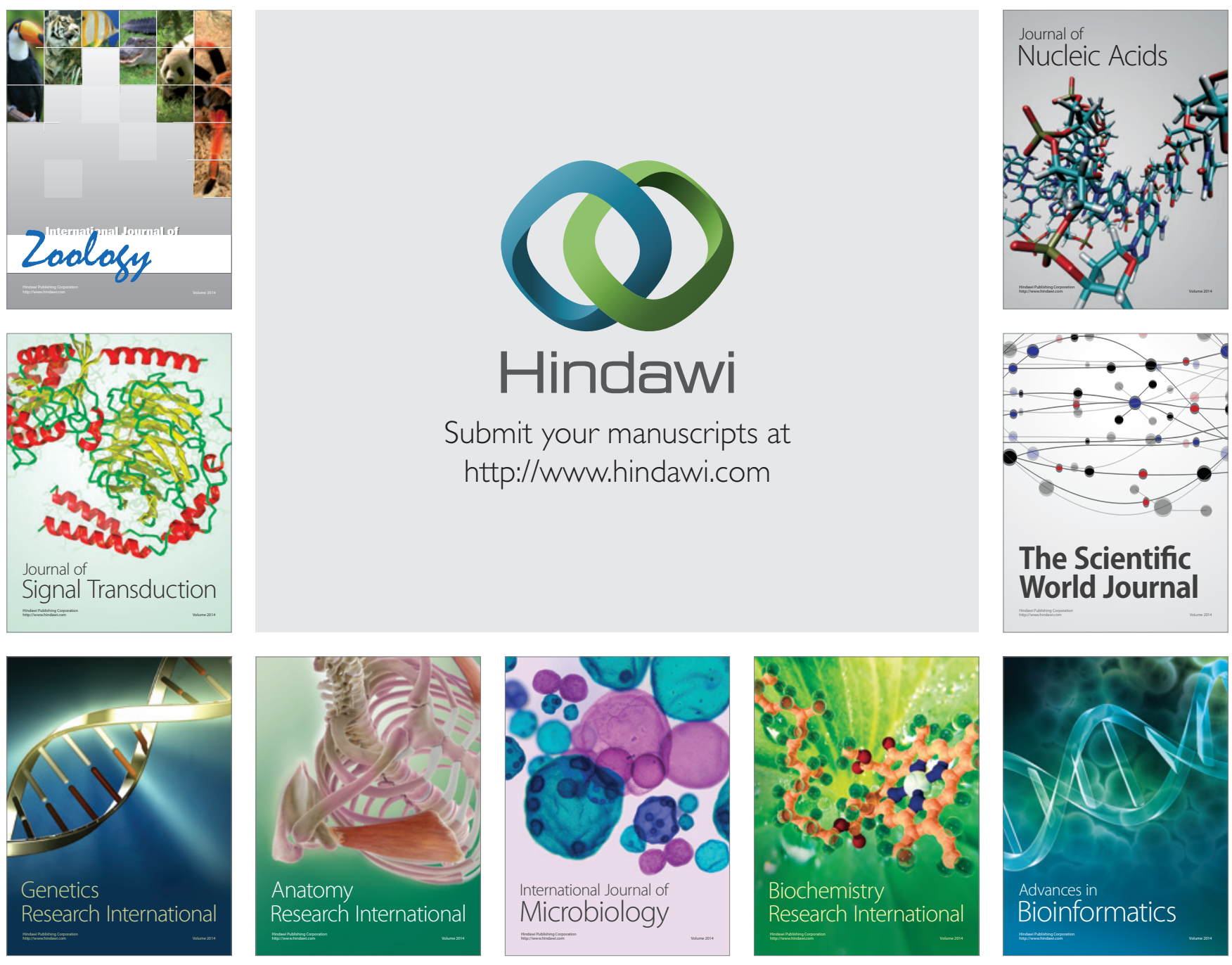

The Scientific World Journal
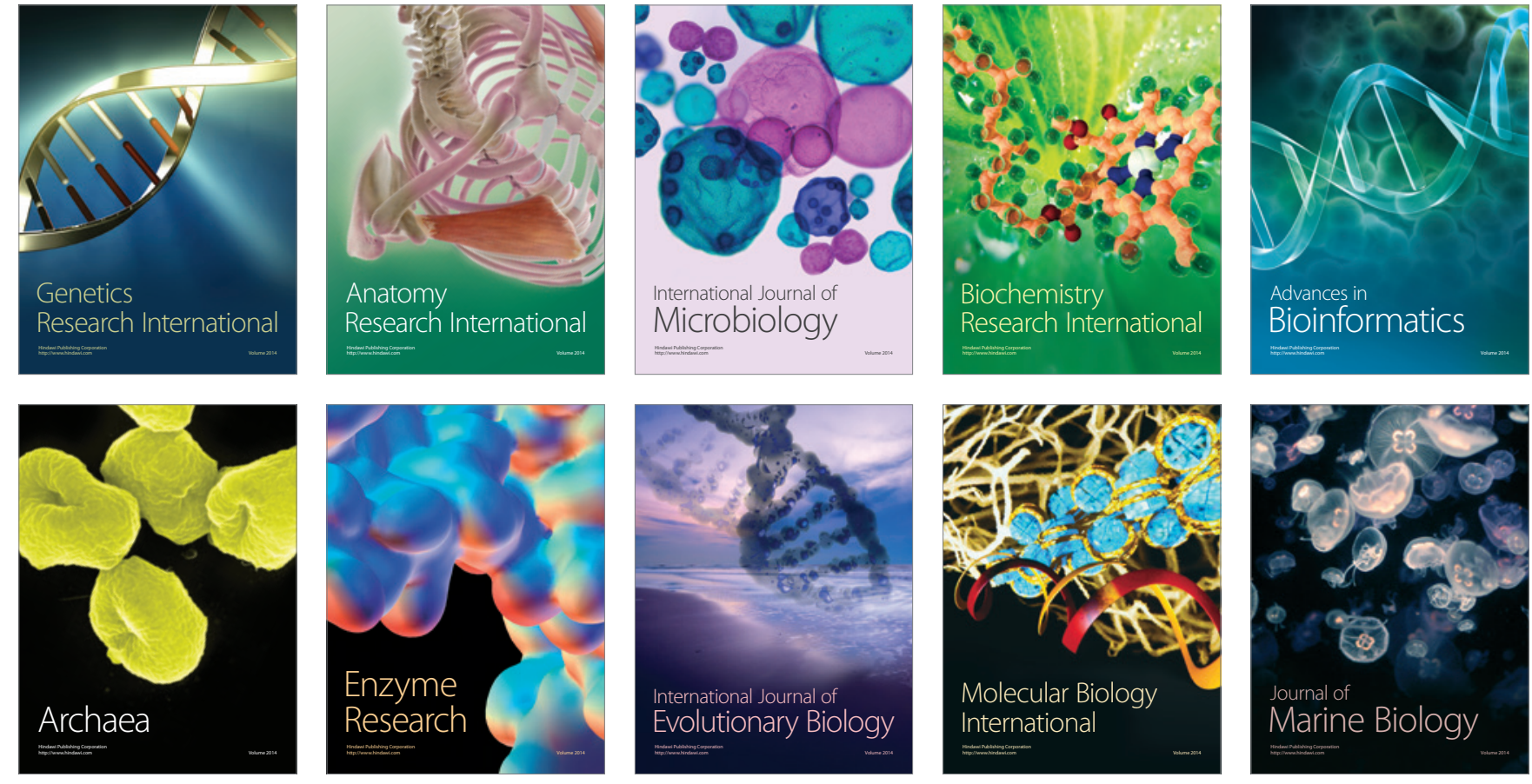